\title{
Theory is acid test for fructose's blood pressure role
}

Fructose is under fire. In recent years, the simple sugar has endured close scrutiny from scientists who claim that it increases the risk of obesity more than its cousin glucose does. Now, some researchers would like to add liver abnormalities and high blood pressure to the list of fructose's offenses, and they offer the theory that one particular molecule-uric acid-could mediate these possible ill effects.

A wide range of foods from fruit to honey naturally contain fructose, and it is often added in the form of high-fructose corn syrup to countless processed staples and soft drinks. "Fructose is safe," says Audrae Erickson, president of the Corn Refiners Association, a national trade group based in Washington, DC. She stresses that it is similar to glucose, which has the same molecular formula as fructose but a different structure, saying "it's an urban legend that our bodies can tell the difference between these sugars."

Although there are scientists who support Erickson's view, others have published studies coming to a different conclusion. For example, one prospective study presented in 2008 found evidence suggesting that soda and fruit juice increased the incidence of gout in men (BMJ 336, 309-312, 2008). Last year, a ten-week trial of 32 overweight or obese individuals found that those who drank beverages containing fructose gained twice as much belly fat than those consuming glucose-sweetened drinks ( $J$. Clin. Invest. 119, 1322-1334, 2009). Meanwhile, a recent analysis of liver biopsies combined with survey answers from more than 400 people found a link between soda intake and liver scarring in people who already had extra fat accumulation in that organ (Hepatology 51, 1961-1971, 2010).

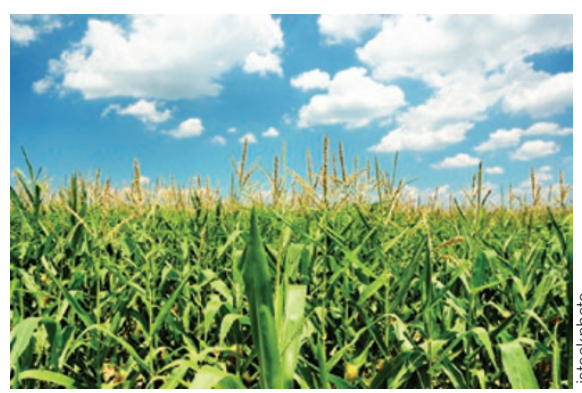

An earful: Fructose in corn syrup attacked.

All these studies together have hinted that excessive fructose intake may pose a problem beyond the calories it adds. "The big breakthrough to me was the recognition that fructose has effects that are independent of energy intake," says Hepatology study co-author Richard Johnson, a nephrologist at the University of Colorado-Denver.

At a symposium held by the International Society of Nephrology in Geneva this summer, Johnson explained his theory that fructose poses a unique problem because the enzyme that metabolizes the simple sugar lacks the same feedback controls as the enzyme that breaks down glucose. As a result of what he describes as "runaway" fructose metabolism, the metabolic byproduct uric acid accumulates within the body's cells. This is notable, according to Johnson, who, among others, has shown that high levels of uric acid in the blood might contribute to hypertension (J. Am. Med. Assoc. 300, 924-932, 2008).

However, not everyone-even Johnson's collaborators-are convinced that uric acid is the primary mediator of whatever ill effects fructose might have on the body. "I think there is validity to that theory, but I don't think that it's the exclusive theory floating around," says Manal Abdelmalek of the Duke University Medical Center in Durham, North Carolina, who led the liver study. An alternative idea, she notes, is that the fructose metabolism might cause direct damage to cells by decreasing levels of the energy-shuttling molecule ATP.

Others say that if uric acid levels go up, it's as a result of an insulin hormone surge after the consumption of any sugar type, including glucose. Gerald Reaven, an endocrinologist at the Stanford University Medical School in California, points to his decades-old research linking high insulin concentrations in the blood to slow excretion of uric acid from the kidneys (J. Am. Med. Assoc. 266, 3008-3011, 1991).

"I'm not sure it's fructose," he says, "but I'm not saying it couldn't be possible."

Roxanne Khamsi

\section{Price of misconduct probes can surpass $\$ 500,000$}

Integrity is priceless, but investigating it doesn't come cheap either. According to a new analysis, misconduct probes can cost institutions upwards of half a million dollars.

Researchers at the Roswell Park Cancer Institute in Buffalo, New York reached that figure by examining the monetary costs of one case at their institution, where a senior scientist was accused of fabricating images and data in a federal grant application (the case is still pending). Their results pegged the direct cost of the investigation thus far at around $\$ 525,000$ (PLoS Med. 7, e1000318, 2010). That total includes $\$ 512,000$ representative of the hours spent on the case by salaried faculty. An additional $\$ 10,000$ went to wages for security, computer forensics, and IT personnel involved in sequestering lab equipment and copying data from notebooks, hard drives and other electronic devices. Clerical support costs added almost $\$ 3,000$.

And that's just the baseline. Alan Hutson, a biostatistician and one of the authors of the paper, describes other potential costs, some unquantifiable. "Sometimes the investigator has three or four NIH grants, and we have to repay that money. Then there's the cost to our reputation that's even worse than the monetary cost. There are the innocent bystanders, such as the graduate students who have to find a new mentor, redo their dissertation or sometimes go to another institution."

Other indirect costs not included in the $\$ 525,000$ figure include man-hours spent on the case by senior administrative officials, the possible loss of pending grant money and the cost of supporting staff who may move to new labs.

With each case costing hundreds of thousands of dollars, the total cost of investigating could be astronomical. In 2007, the latest year with such data available, research institutions filed 217 allegations of misconduct to the US Office of Research Integrity, according to agency officials. A 2009 survey of scientists found that $2 \%$ of respondents admitted to committing scientific misconduct (PLoS One 4, e5738, 2009).

Clearly, research misconduct isn't endemic to biomedicine, but when it happens-as in a recent case at the Kreitchman PET Center of Columbia University, where federal investigators found that psychiatric patients were injected with drugs known to contain impurities - the human cost is front and center.

Roxanne Palmer 